\title{
Privatização tcheca: de propriedade pública a propriedade pública em cinco anos?
}

\author{
PAVEL MERTLÍK
}

\begin{abstract}
REForma ECONÔMICA tcheca (ou tchecoslovaca) pode ser assumida como um caso representativo do que é convencionalmente chamado de tera1 pia de choque. Consiste essa terapia de três elementos cruciais: estabilização macroeconômica, liberalização de mercado e privatização, seqüência essa que foi respeitada na referida reforma. Recentemente, o modelo generalizado dessa estratégia e de sua lógica, rotulada como O Modelo Sachs, foi descrito em detalhes e analisado criticamente por Chlumsky (1994).
\end{abstract}

O ponto de partida da reforma - a política de estabilização baseada na diminuição programada da demanda nacional agregada - consistiu de políticas monetárias e fiscais rígidas e restritivas, ou quase-restritivas, elevadas taxas de juros nominais, redução dos gastos públicos reais, alto nível de tributação, excedente orçamentário, baixa taxa de câmbio e estabilidade da moeda nacional. Sua estabilização nominal em nível bem abaixo da paridade do poder de compra durante um longo período serviu (além de seus efeitos pró-exportação e antiimportação) como a âncora nominal monetarista, isto é, um padrão para todos os preços absolutos e relativos da economia (inclusive salários, aluguéis etc.).

Após as medidas da política de estabilização de 1990, seguiu-se a liberalização de janeiro de 1991 (1). O processo de privatização (como a parte mais importante da mudança institucional) teve o seu início no outono de 1990, mas em grande medida somente no início de 1991; sua primeira fase importante foi concluída (pelo menos formalmente) em meados de 1993 e, a segunda, na primavera de 1995. Entretanto, existe ainda parte da propriedade sob controle estatal - empresas estatais, instituições orçamentárias e participativas (2) além de ações do governo em empresas públicas limitadas - que deverá ser privatizada de acordo com as decisões governamentais em anos vindouros.

\section{O formato (design) da privatização}

Em $1^{\circ}$ de janeiro de 1991 o setor estatal, juntamente com as cooperativas, ainda estava produzindo aproximadamente $98 \%$ do PIB tcheco Os formuladores governamentais do programa de privatização declararam a intenção de transferir, em ritmo acelerado, de 70 a $80 \%$ das empresas estatais (EEs) para controle privado. $\mathrm{O}$ governo selecionou inicialmente dois métodos como base do processo 
de privatização: corporativização e venda subseqüente das (ex-)EEs a organismos privados; e o método voucher, isto é, técnica não-tradicional de privatização, baseada na livre distribuição de ações das antigas EEs à população. Um terceiro método foi acrescentado pelo Parlamento aos dois mencionados - a restituição natural - ou seja, a restituição da propriedade nacionalizada aos proprietários originais ou a seus respectivos herdeiros, de acordo com os direitos de propriedade detidos em 25 de fevereiro de 1948, data da nomeação do governo que deu início ao processo de transformação da economia tchecoslovaca em uma economia de planejamento central (EPC) do tipo soviético. A restituição natural, contudo, dizia respeito apenas à propriedade individual ilimitada, não contemplando parcerias e ações em empresas privadas ou públicas limitadas. $\mathrm{O}$ arcabouço do curso da privatização foi definido por leis de privatização e de restituição (3).

De acordo com a Lei da Pequena Privatização, a propriedade envolvida era vendida em leilões dos quais poderiam participar pessoas físicas ou empresas privadas (com exceção de cooperativas) sem a participação de capital estrangeiro. Caso a propriedade levada a leilão não fosse vendida, novo leilão era organizado (repetido), no qual se admitia a participação de estrangeiros e firmas do exterior (ao contrário do que acontecia no primeiro). Os primeiros leilões da Pequena Privatização ocorreram no final de 1990. Além de pequenas empresas (lojas, pequenas unidades comerciais prestadoras de serviços etc.), também fábricas que empregavam várias centenas de funcionários foram vendidas nesse processo. O último ponto foi conseqüência do fato de não haver na Lei da Pequena Privatização uma definição legal da escala da propriedade a ela sujeita. Em vez disso, havia uma definição funcional que impedia a privatização de qualquer propriedade que fosse ou pudesse ser objeto de restituição natural, ou sobre a qual pendesse responsabilidade por passivos não-próprios, em outras palavras, passivos que não de capital próprio. Na prática, não foram as empresas, mas o capital físico como tal (extraído das EEs) é que foi vendido ou alugado nos leilões da Pequena Privatização; entretanto, os passivos que oneravam os ativos ofertados foram deixados em suas EEs mães. A decisão sobre qual propriedade particular seria leiloada de acordo com a Lei da Pequena Privatização estava totalmente sob a competência das Comissões Distritais de Privatização, instituídas e organizadas com esse fim pelo governo nacional e por seus respectivos corpos executivos regionais (autoridades distritais).

Os leilões realizados de acordo com a Lei da Pequena Privatização terminaram basicamente no final de 1992, quando a parte prevalente da propriedade designada pelas comissões distritais para tal forma de privatização foi vendida ou alugada (todavia, vários leilões foram ainda organizados mais tarde). Desde seu início até o final de 1993, houve a venda ou locação de 24.359 unidades de propriedade nos leilões da Pequena Privatização, totalizando, em valor de mercado, quase CZK 31 bilhões (US\$ 1,1 bilhões).

No processo de leiloamento, ocorreram vários fenômenos injustos como a maciça e silenciosa participação do capital estrangeiro através de pessoas locais 
contratadas que atuavam como quase-compradores; existe forte suspeita de que parte substancial desse capital era constituído de dinheiro sujo, originário de atividade econômica ilegal, como o proveniente do mercado de drogas, entre outros. Mesmo a Interpol informando oficialmente ao governo que os leilões seriam uma boa oportunidade para "lavagem de dinheiro", isso foi praticado em larga escala. Outras práticas injustas foram ainda observadas no processo da Pequena Privatização: de origem doméstica, representaram especulações e manipulações em leilões por parte de gangues organizadas, que levaram ao estabelecimento de preços artificiais (extremamente elevados ou extremamente baixos) para algumas empresas de interesse especial para essas gangues. Tais ocorrências não eram afetadas legalmente na República Tcheca àquela época devido às lacunas existentes na legislação.

O processo da Pequena Privatização representou, em si, imensa experiência social, que teve como objetivo principal a criação das novas classes burguesa e pequeno-burguesa. Mas seu significado foi secundário se comparado com o alcance e o impacto das restituições naturais e, obviamente, também com o significado da Grande Privatização, experimento social sem precedentes, anunciado pelo governo em 1990, elaborado em detalhe durante 1990-91, e recebendo sua base legal na Lei da Grande Privatização de 1991.

O processo da Grande Privatização iniciou-se em fevereiro de 1992, embora já estivesse em andamento desde o início do outono do ano anterior. A organização desse processo baseou-se na submissão de projetos individuais de privatização de todas as unidades de propriedade estatal que deveriam ser privatizadas dentro desse esquema: todas as EEs, além de outras unidades de propriedade estatal, com exceção daquelas já escolhidas pelas Comissões Distritais para a Pequena Privatização; as naturalmente restituídas e aquelas arroladas em uma lista especial de EEs entre outras unidades de propriedade pública que não deveriam ser privatizadas durante os próximos cincos anos (a lista foi aprovada pelo governo em 1991 e contém itens como ferrovias, correios, universidades etc., com cerca de 500 itens); os projetos foram submetidos à aprovação do governo. Embora as administrações das EEs fossem legalmente obrigadas a preparar e submeter projetos de privatização de suas empresas, todas as demais pessoas físicas e jurídicas - tchecas e estrangeiras - tiveram o direito de submeter seus próprios projetos de privatização, denominados competitivos, idealizados para privatizar algumas das EEs ou parte delas (uma fábrica, por exemplo). Portanto, o Ministério da Administração da Propriedade Nacional e sua Privatização (MAPNP), na maioria dos casos, podia escolher entre dois ou vários projetos de privatização referentes à mesma empresa - em média, foram submetidos cerca de 4 a 5 projetos para cada parte privatizada da antiga propriedade estatal. Além do método voucher, da venda direta a um proprietário designado (isto é, sem concorrência de aquisição), da concorrência para aquisição, do leilão, da livre transferência de ações a uma autoridade local, a um fundo de pensão ou um fundo de seguro de saúde, a venda de ações no mercado de capitais é também técnica aplicável sob as disposições da Lei da Grande Privatização. Na maioria dos proje- 
tos de privatização, houve a aplicação de uma combinação de diferentes técnicas (mescla de privatização).

O procedimento de transformação da propriedade dentro do esquema da Grande Privatização foi o último: depois da aprovação do projeto de privatização de uma EE (de uma organização orçamentária ou participativa) pelo governo, a empresa ou organização era transferida do respectivo ministério (na qualidade de seu proprietário) para o Fundo Nacional de Propriedades (FNP), um organismo público criado pelo governo para a materialização dos projetos aprovados de privatização, o controle da propriedade privatizada antes de sua transferência ao novo proprietário e a administração da propriedade (ações) mantida na carteira do FNP. Este era subordinado ao MAPNP e supervisionado por ele. Em seguida, o FNP vendia a propriedade da empresa ou organização transferida, ou parte dela, ao(s) novos(s) proprietário(s), de acordo com o projeto de privatização aprovado (ou seja, diretamente ao proprietário designado, ao vencedor de uma concorrência de aquisição ou de um leilão organizado pelo FNP). Assim, transferia a propriedade liberada para o novo proprietário ou liqüidava a empresa ou organização e, no mesmo momento, colocava a sua propriedade como entrada de capital em outra empresa pública limitada recém-estabelecida. A seguir o FNP, novamente de acordo com o projeto de privatização aprovado, vendia as ações da companhia pública limitada recém-estabelecida (novamente ao proprietário designado, ao vencedor de uma concorrência de aquisição ou no mercado de capital organizado - geralmente significando a Bolsa de Valores de Praga ou o mercado eletrônico tcheco que permite acesso direto a ele, o Sistema RM). Poderia ainda transferir livremente as ações ao novo proprietário, ou colocá-las na privatização voucher. Por último, nem por isso menos importante (novamente de acordo com o respectivo projeto de privatização aprovado), mantinha as ações temporariamente (antes de uma venda futura) ou permanentemente, em sua carteira.

O processo da Grande Privatização foi organizado em duas ondas de privatização, definidas pela lei como um "processo específico de oferta e procura da propriedade nacional indicada física e temporalmente". Para a primeira onda, o governo selecionou 2.210 EEs entre as cerca de 4.400 qualificadas. A inclusão das empresas no cronograma das ondas de privatização foi puramente pragmática - os casos menos problemáticos foram colocados na primeira onda, enquanto os mais problemáticos (dúvidas quanto ao direito de propriedade, ao tamanho dos passivos etc.), em sua maioria adiados para a segunda onda. Além disso, a privatização de algumas indústrias foi protelada para a segunda onda como um todo (por exemplo, parte significativa da indústria química, toda a indústria farmacêutica, indústria de mineração de carvão, de metalurgia de ferro, além de fazendas estatais e florestas, entre outras). A primeira onda terminou em meados de 1993; paralelamente, a segunda onda já havia sido iniciada no primeiro semestre de 1992 através de sua fase preparatória, terminando na primavera de 1995 (4).

Compreendamos quão imensa foi a mudança social que o processo da Grande Privatização representou. O básico do método voucher de privatização 
refere-se à idéia da livre distribuição da riqueza nacional à população em base algo igual, mas não igualitária; o governo acreditava que esse método seria socialmente justo por oferecer a mesma oportunidade para todos. Ao mesmo tempo, de acordo com a retórica governamental, era economicamente racional, pois principalmente só salvaguardava que a elite social (com melhor conhecimento do mercado e maior capacidade para desenvolver expectativas racionais sobre o futuro incerto e, nesta base, capaz de tomar decisões corretas) poderia ser bem-sucedida. Em outras palavras, o governo acreditava que, graças ao método voucher de privatização, a riqueza nacional cairia rápida e seguramente nas mais habilitadas mãos existentes na sociedade, isto é, nas mãos das pessoas com maior capacidade da nação - indivíduos dotados da mais alta sabedoria, habilidade e educação. Conseqüentemente, a ordem social retornaria imediata e eficientemente do perigoso e distorcido experimento comunista, para uma espécie de ordem hayekiana espontânea, ou a um estado natural de coisas, no qual os melhores são os mais ricos e vice-persa.

O interesse do público tcheco na privatização voucher foi relativamente baixo durante os primeiros dois meses do período de registro da primeira onda (novembro-dezembro de 1991). Somente algumas centenas de milhares de pessoas inscreveram-se até o final do ano, provavelmente devido à não-confiável, fraca e tola campanha publicitária governamental, divulgada em curtos clips de $\mathrm{TV}$, no estilo Coca-Cola, que não forneciam praticamente qualquer informação sobre o programa como um todo para o público em geral. Entretanto, uma mudança súbita e radical ocorreu em janeiro de 1992.

Foi a época da emergência de uma campanha publicitária agressiva e ruidosa, veiculada em todos os meios de comunicação de massa pelos inúmeros Fundos de Privatização de Investimento (FPIs) recém-criados, empresas públicas limitadas organizadas por bancos, companhias de seguro, firmas de consultoria e várias outras empresas privadas, além de algumas pessoas físicas (o pré-requisito para realizar tais negócios era provê-los com um capital acionário de pelo menos CZK 1 milhão, aproximadamente US\$ 35,7). Os FPIs são empresas públicas limitadas, que lançam ações contra o recebimento de vouchers de investimento. $\mathrm{Na}$ Grande Privatização, eles utilizaram os vouchers de investimento coletados do público para a compra de ações das antigas EEs corporativizadas. Um FPI podia controlar até $20 \%$ das ações de uma empresa, de acordo com a lei.

A campanha de alguns dos FPIs (aproximadamente 260 tinham sido criados, mas apenas doze transformaram-se realmente em grandes portadores de vouchers durante a primeira onda) baseou-se na promessa pública de que recomprariam do público as suas próprias ações (isto é, dos seus acionistas) um ano após a transferência das ações de EEs adquiridas por um preço, no mínimo, dez (ou até 15) vezes o valor gasto por seus acionistas para obter seus vouchers de investimento, alocados ao respectivo FPI. Essa promessa pública foi o incentivo definitivo para que o público participasse da privatização voucher. Dessa forma, as pessoas em massa perceberam que os vouchers de investimento e as ações que podiam ser obtidas por meio deles eram realmente algo de valor, que representavam 
uma propriedade real. Como resultado desse aprendizado social, $82 \%$ dos tchecos adultos tchecos inscreveram-se como portadores de vouchers de investimento. Cada portador registrado recebeu um talão de vouchers com mil pontos de investimento, por uma taxa nominal de CZK 1.035 (US\$ 37), na época representando cerca de $20 \%$ do salário médio mensal. O valor contábil das ações oferecidas proporcional a um talão de vouchers era de cerca de CZK 60.000 (US\$ 2.143). Os primeiros quase seis milhões de portadores de vouchers de investimento alocaram $72,2 \%$ de seus pontos em um ou mais FPIs, enquanto somente os demais $27,8 \%$ foram utilizados diretamente para investimento em ações de empresas.

Em termos globais, na primeira onda da Grande Privatização houve aprovação e materialização de 3.858 projetos para as 2.210 EEs selecionadas (a diferença entre o número de projetos aprovados e o de EEs privatizadas demonstra a desconcentração realizada dentro do processo de privatização: significa que como um dos resultados da primeira onda da Grande Privatização, o número de empresas cresceu de 2.210 para 3.858 , ou seja, quase $75 \%$ ). O patrimônio total da propriedade privatizada era de quase CZK 469 bilhões (US\$ 16,75 bilhões); mais de CZK 198 bilhões (US\$ 7,7 bilhões) dele, isto é, mais de 42\%, foram privatizados por vouchers. Uma participação acionária de quase CZK 10 bilhões (US\$ 357 milhões) foi transferida gratuitamente às municipalidades, fundos de seguro social etc.; outra, de mais de CZK 40 bilhões (1,4 bilhões) foi vendida em leilões, concorrências de aquisição ou diretamente a um proprietário designado. $\mathrm{O}$ patrimônio restante, de mais de CZK 220 bilhões (US\$ 7,8 bilhões), ou seja, cerca de $47 \%$ foi somente corporativizado e até o final de setembro de 1994, mantido na carteira do FNP (Buchtíková, 1995; Skalicky, 1994).

Como já mencionado, tal propriedade corporativizada, em sua maior parte, tornou-se objeto de privatização adicional por diversas formas: vendida no mercado de capital, em concorrências de aquisição, em venda direta, em venda aos empregados como ações, transferida livremente àqueles com direito à restituição (de acordo com suas reivindicações nos casos em que a restituição natural não foi possível), a municipalidades ou a fundos de seguro social. Além disso, parte das ações era mantida, temporária ou permanentemente, no FNP, na forma de ações do governo em empresas públicas limitadas. O FNP acredita que terminará a venda de seus ativos, conforme programado, até os últimos anos desta década (digamos, em 1998). As vendas de ações da carteira do FNP (se não determinadas diretamente no projeto de privatização, isto é, se somente definidas como temporariamente mantidas no FNP) estão sujeitas à aprovação ou à decisão governamental. O governo pode ainda mudar sua decisão original de manter permanentemente parte das ações no FNP e definir sua venda ou livre transferência.

Dessa forma, torna-se evidente que a mera corporativização (mudança do status legal da empresa, de EE, de organização orçamentária ou de organização participativa para empresa pública limitada, cujas ações são mantidas pelo FNP, ao contrário de títulos de propriedade de EEs e de organizações orçamentárias e participativas, detidos por vários ministérios) é também considerada, na realidade tcheca contemporânea, como forma de privatização. Conseqüentemente, o 
registrado como propriedade privatizada nas estatísticas da privatização tcheca representa um conjunto heterogêneo de direitos de propriedade, no qual o(s) proprietário(s) pode $(\mathrm{m})$ ser privado(s) ou público(s). A definição funcional do conceito de privatização e propriedade privatizada, portanto, é somente uma forma negativa relacionada às EEs, organizações orçamentárias ou participativas: privatizado significa algo que tinha a forma de EE (organização orçamentária ou participativa; ou seja, alguma forma não-acionária de propriedade pública) e já não tem mais. Pode-se, portanto, concluir concisamente que privatizado, na República Tcheca, significa apenas transformado de propriedade pública nãoacionária em propriedade acionária (pública ou privada).

De acordo com as informações do MANPNP de dezembro de 1994 (Skalicky, 1994), até o final de setembro do mesmo ano foram privatizadas $3.403 \mathrm{EEs}$, organizações orçamentárias e participativas, totalizando um patrimônio de mais de CZK 912 bilhões (US\$ 32,5 bilhões), no curso da Grande Privatização; a extensão da mera corporativização contida nesses dados não foi divulgada. Isto, contudo, significa que, até a data mencionada, 1.193 organismos legais, em propriedade pública não-acionária (EEs, organizações orçamentárias, organizações participativas) com capital superior a CZK 443 bilhões (US\$ 15,8 bilhões) foram privatizados no curso da segunda onda, ainda em andamento. Considerada toda a Grande Privatização até o final de setembro de 1994, 120 unidades de propriedade foram integral ou parcialmente vendidas a investidores estrangeiros. O capital desses investimentos (take-overs) totaliza mais de CZK 25 bilhões (US\$ 892 milhões) - menos de $3 \%$ de todo o patrimônio privatizado ou corporativizado no esquema da Grande Privatização. A propriedade restante que deveria ter sido privatizada ou corporativizada apenas até o final da segunda onda representava, àquela época, um patrimônio de CZK 31 bilhões (US\$ 1,1 bilhões).

O restante da propriedade não-acionária do Estado, após o fim da segunda onda da Grande Privatização (isto é, propriedade na forma de EEs, organizações orçamentárias e participativas) corresponderá a aproximadamente CZK 500 bilhões (US\$ 17,8 bilhões) de capital acionário (Skalicky, 1994). Parte dele também será privatizado; contudo, o governo tenciona privatizar gradualmente somente uma pequena fração, ou seja, cerca de 250 unidades com capital acionário totalizando vários bilhões de CZK, de um conjunto de 4.429 , de propriedade não-acionária do Estado registradas no final de 1994. Mas essa privatização adicional - às vezes chamada de a terceira pequena onda da Grande Privatização inclui itens importantes como, por exemplo, as ferrovias.

De acordo com informações mais recentes do FNP (final de abril de 1995), o Fundo tinha um patrimônio de CZK 279 bilhões (US\$ 10 bilhões) em sua administração; quase $25 \%$ desse patrimônio estava em controle permanente do FNP, representado por ações de 50-60 companhias estratégicas nas quais o governo, de acordo com os respectivos projetos de privatização aprovados, tinha se apresentado como investidor estratégico (majoritário ou minoritário). Esse patrimônio de CZK 279 bilhões (US\$ 10 bilhões) também representava cerca de $40 \%$ (sic!) de todas as ações que até então o FNP já tinha possuído em sua carteira. 


\section{Disposição da propriedade resultante da privatização}

Se se tomar como base somente registros estatísticos, é difícil compreender o resultado da privatização até agora realizada. Mais adequado se torna imaginar qual a aparência da estrutura dos direitos de propriedade da economia tcheca. Em todas as formas de privatização, e também no processo da restituição natural, o controle sobre importante parte da economia passou às mãos de indivíduos ou empresas privadas (não exclusivamente, mas predominantemente tche-

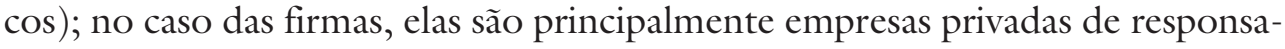
bilidade limitada, formadas por administradores das antigas EEs e fortemente endividadas com os bancos tchecos; graças aos créditos que detinham, puderam realizar compras alavancadas para assumir o controle. Na maioria dos casos, entretanto, tal fato se refere somente a empresas de pequeno e médio portes.

As grandes empresas, e também a maioria das de médio porte, são normalmente controladas pelos FPIs. Naturalmente existem alguns casos, embora excepcionais, que fogem à regra: várias dezenas de empresas colocadas em joint ventures com investidores diretos estrangeiros, ou a eles vendidas (sendo o mais famoso o caso da Skoda, a.s., Mladá Boleslav, que ficou sob o controle da Volkswagen). Há ainda alguns casos - talvez menos de dez - em que uma grande empresa é agora controlada por um indivíduo ou firma privada tcheca (o mais relevante deste grupo é, sem dúvida, o caso de um dos pilares da economia tcheca, Skoda Koncern, a.s., controlado por seu presidente e principal acionista L. Soudek, provavelmente hoje o tcheco mais rico do país).

Não obstante, enfatizamos uma vez mais, que a regra é uma empresa tcheca padrão ser controlada por um grupo de FPIs. Além disso, na maioria das empresas privatizadas no esquema voucher, o FNP ainda possui ações, mesmo que de forma minoritária. Assim, a pergunta que se coloca é: quem são os proprietários dos FPIs? Entre os maiores FPIs, com raras exceções, como a Harvard Capital es Consulting, TSE e C.S. Funds (controlados privadamente por indivíduos tchecos, com grande probabilidade de terem, por trás deles, algum capital estrangeiro não-conhecido) e Creditanstalt ou Vseobecná úverová banka (controlados por bancos estrangeiros, o primeiro austríaco e o segundo eslovaco - mas com importante participação do FNP theco em sua estrutura de propriedade), os demais são controlados pelos principais bancos tchecos - nominalmente pelos Cinco Grandes, isto é, o grupo de gigantes tchecos do setor bancário: Ceská sporiteina, a.s., Komercní banka, a.s., Ceskolovenská obchodníbanka, a.s., Investicni a postovni banka, a.s. e Agrobanka, a.s., e pela maior empresa tcheca de seguros (ex-monopólio estatal) Ceská pojistovna, a.s.

Continuando: quem controla os Cinco Grandes? O Agrobanka, a.s. (o menor deles) é controlado por empresas tchecas - as ex-EEs, a maioria delas privatizadas pelo esquema voucher, e por outros bancos; o Ceskoslovenská obchodni banka é controlado pelo FNP e pelo FNP da Eslováquia; os três restantes - dos quais o Ceská sporiteina e o Komercni banka são de longe os maiores bancos do 
país - têm seus pacotes controladores de ações em uma administração permanente da carteira do FNP, o mesmo acontecendo com a companhia de seguros Ceská pojistovna: Além disso, existem numerosas propriedades cruzadas de importantes pacotes minoritários de todos esses bancos. A Lei dos Bancos proíbe a venda de ações de bancos tchecos fora do país, sem especial permissão do governo. Assim, o círculo parece estar completo.

Podemos concluir, portanto, que os tchecos têm agora literalmente, como resultado de mais de cinco anos de privatização, um excelente exemplo da propriedade recombinante de David Starks (Stark, 1994) ou, talvez, um capitalismo financeiro nacional (ou um socialismo, se houver quem goste) que lembra aquele da Alemanha, mas com um papel desempenhado pelo governo nacional como investidor central que controla indiretamente (via FNP e sua rede de capital acionário) a espinha dorsal de quase toda a economia. É o que resta das atividades de privatização dos últimos anos; se quisermos saber quem controla uma típica empresa tcheca privatizada, encontraremos principalmente uma complicada cadeia de ações, em cuja extremidade se encontra o FNP. De lado, outra questão que se coloca refere-se à governança corporativa: aqui, o papel dos administradores - e dos bancos, na qualidade de proprietários e credores (significando, das administrações do banco!) - cresceu significativamente, como ver-se-á no próximo tópico. O melhor reflexo teórico da "privativação, estilo tcheco", até agora, é o fornecido por Mlcoch (1995).

Em 1993 - como resultado do processo de privatização realizado até então, e também devido ao crescimento dinâmico do genuíno setor privado originado do zero após 1989 (por mais impressionante que seja, este é, apesar de tudo, prevalentemente limitado ao setor de serviços), a participação do setor privado na formação do PIB, pela primeira vez, excedeu à participação do setor público (conforme as estatísticas oficiais, segundo as quais - de acordo com a lógica descrita acima - todas as companhias públicas limitadas são consideradas firmas privadas). Em 1994 (como resultado do progresso da segunda onda da Grande Privatização) tal mudança na estrutura setorial da formação do PIB teve aceleração ainda maior. Em comparação com a situação anterior à privatização, $O$ que ocorreu até agora constitui mudança real; mas, à luz do já mencionado, ainda está muito longe da simples idéia de propriedade privada da ideologia econômica neoliberal e, explicitamente, da tradição intelectual da escola austríaca que era, pelo menos do ponto de vista da retórica oficial do governo tcheco, tão importante para a construção do formato da privatização tcheca. Em lugar do proprietário individual responsável, emergiu uma nova - ou talvez quasenova - estrutura hierárquica (Mlcoch, 1995; para ilustração, veja-se o diagrama apresentado a seguir). Entretanto, o papel desempenhado até agora pelo FNP parece, na maioria dos casos, muito passivo, de tal forma que se poderia imaginar a economia tcheca consistir de um monstro piramidal com a cabeça adormecida. Mas será que a cabeça do monstro está realmente dormindo?

Por outro lado, essa nova estrutura hierárquica é frágil e instável. A principal razão para tal instabilidade é o comportamento dos FPIs, que seguem exer- 
cendo seu duplo e conflitante papel na economia. Por um lado, são holdings financeiras estranhas e, pelo menos algumas delas, estão tentando desempenhar o papel de proprietários ativos (e responsáveis?); por outro lado, elas de fato têm obrigações para com seus pequenos acionistas (clientes), isto é, crescer, para manter os preços de mercado de suas próprias ações e render dividendos.

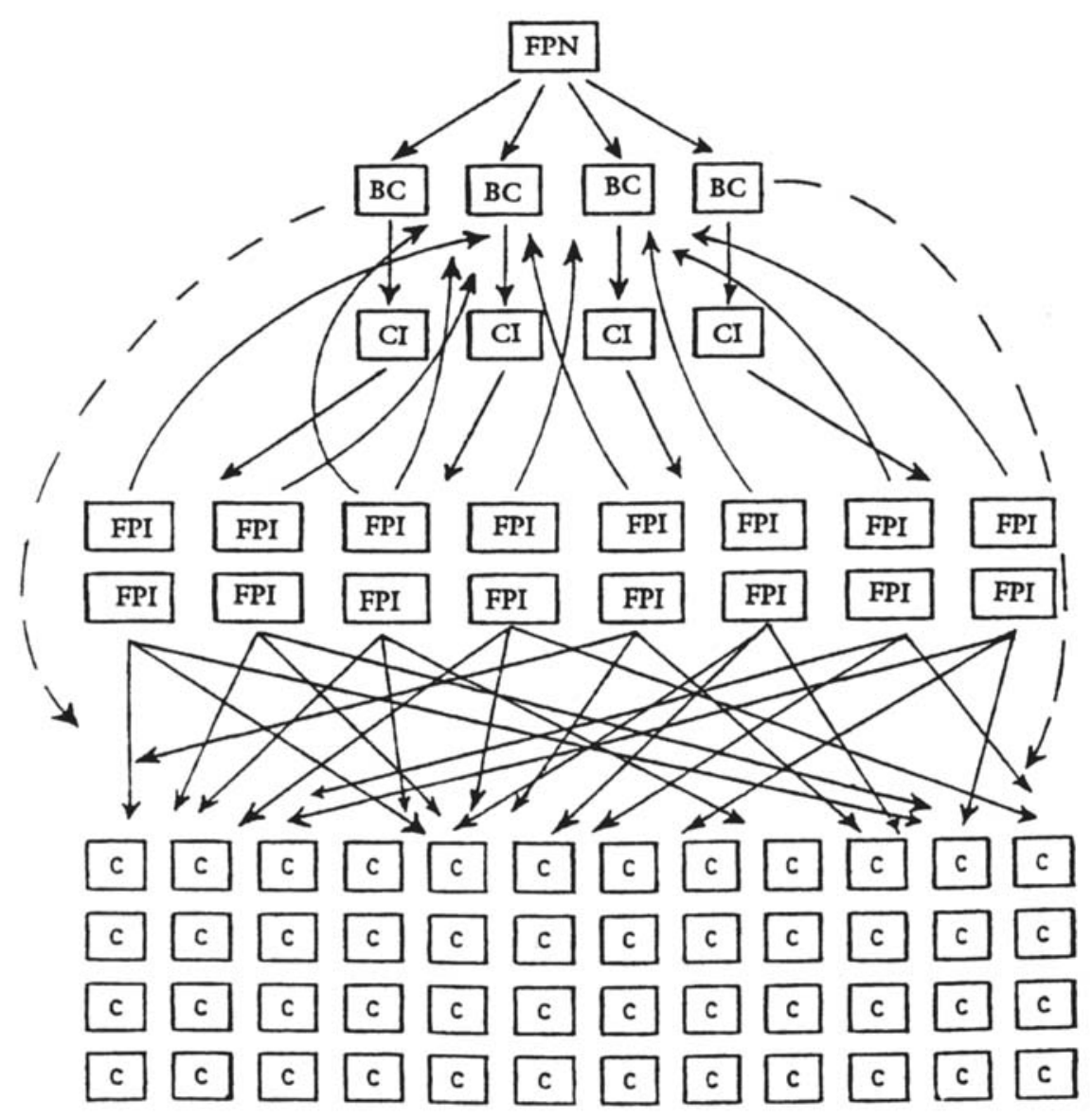

FNP $=$ Fundo Nacional de Propriedades FPI $=$ Fundo de Privatização de Investimento $\mathrm{BC}=$ Banco Comercial $\mathrm{C}=$ Companhia $\quad \mathrm{CI}=$ Companhia de Investimento controle de propriedade $\quad-\ldots-\ldots \rightarrow$ créditos

Figura 1: Estrutura de propriedade da economia tcheca

Como satisfazer este segundo papel dos FPIs e as obrigações dele resultantes, no momento em que os mercados de capital estão deprimidos devido ao excesso de oferta sobre a demanda, quando os preços de mercado dos valores 
mobiliários estão, de forma geral, baixos e a maioria das empresas não auferem lucro suficiente e seus dividendos são baixos ou iguais a zero? A única maneira de obter retorno e satisfazer os acionistas (e também, não menos importante, os credores) é vender parte da carteira. Essa necessidade é também forçada pela subotimalidade e baixa qualidade das carteiras de todos os FPIs, nas quais as ações das empresas são altamente dominantes e outros ativos - mais líquidos como obrigações, depósitos bancários, imóveis etc., negligenciáveis ou marginais. O problema dos FPIs não se refere somente à manutenção corrente da qualidade de sua carteira, mas à necessidade de sua profunda restruturação. Quais ações são oferecidas em primeiro lugar pelos FPIs, quando apenas poucas delas têm realmente valor e liqüidez? É óbvio que, em primeiro lugar, apenas as ações "boas" por existir alguma demanda somente para elas. Mas, em princípio, a maioria dos FPIs está disposta a vender quaisquer ações de sua carteira, caso receba uma proposta atrativa.

Também os pequenos acionistas - ex-portadores de vouchers - revelam suas preferências por liqüidez e gradualmente vendem suas ações. Conseqüentemente, parece estar chegando um dramático período de restruturação secundária dos direitos de propriedade - ou a privatização verdadeira seguindo-se à privatização formal. Conforme afirmam alguns administradores de FPIs e os corretores da Bolsa de Valores de Praga (confirmado por freqüentes reportagens na imprensa sobre novas aquisições), é neste exato momento que os grandes pacotes de ações das companhias tchecas estão sendo negociados - contudo, quase que exclusivamente fora dos mercados de capital oficiais, na forma de negócios diretos à margem do Centro de Valores Mobiliários. Esse novo fenômeno, ocorrido a partir de 1995, pode provavelmente ser identificado com a ameaça da "venda barata da economia nacional" prevista por alguns críticos da privatização voucher no princípio da década de 90, antes do início do experimento.

A falta de proteção aos acionistas minoritários (e às empresas) contra aquisições hostis de controle acionário (no sistema legal tcheco, não existe legislação alguma que proteja os direitos dos acionistas minoritários) favorece ambiente para essa silenciosa privatização secundária.

\section{O modo de operação do antigo setor estatal}

Se avaliarmos o modo de operação econômica do setor estatal ou do antigo setor estatal da economia tcheca até o final de 1993, observamos que, na verdade, somente mudanças menores se materializaram. A estrutura geral na qual o sistema estava funcionando - restrições orçamentárias brandas, comportamento monopolista e inexistência de falência de empresas em crise financeira continua de maneira quase idêntica àquela de antes do início da reforma: desta vez, porém, sem subsídios, mas com crescentes más dívidas, dos bancos e más contas a receber, das empresas. Do ponto de vista desse quadro esmagador, o esperado "choque de mercado" de fato não ocorreu antes de 1993. Por outro lado, esperar uma onda de falências como um processo isolado não parecia realista, mesmo quando os processos para uma profunda restruturação interna estavam 
sendo realizados com sucesso ou, no mínimo, iniciados na maioria das empresas tchecas. Ficou comprovado que a sua capacidade de se adaptar a mudanças e choques externos excedia a todas as expectativas. Mais ainda, já era evidente nessa época que o inevitável processo futuro de liquidação de firmas inviáveis seria principalmente gradual, suave e pouco dramático.

Em 1994, o montante do endividamento mútuo e da insolvência das firmas da economia tcheca parecia ter começado a diminuir. Nesse ano houve certa estabilização financeira na esfera empresarial tcheca, quando muitas empresas envidaram esforços no sentido de se desfazer dos encargos referentes às dívidas e às contas a receber insolváveis (insolvência e endividamento excessivo, em termos gerais). Aparentemente, a restrição orçamentária das empresas ficou mais rígida: as firmas de vários setores da indústria mudaram suas políticas de vendas e agora estão exigindo estritamente pagamento à vista, ou imediato, da maioria dos clientes (com exceção do grupo dos melhores clientes, ou seja, grandes clientes, regulares e de longa data, financeiramente estáveis; tais firmas geralmente desfrutam de tratamento preferencial no tocante aos pagamentos, fruto de sua confiabilidade). Assim, a redução do fardo dos maus pagadores das empresas (quando conseguida) é resultado de sua adaptação microeconômica. Esta adaptação é também correlacionada ao aumento da concorrência e ao endurecimento do ambiente competitivo na economia (contudo, ainda altamente imperfeita em termos microeconômicos).

Por outro lado, o procedimento de classificar as firmas em boas (viáveis) e más (inviáveis) - ou uma seleção natural, se o leitor preferir - aparentemente foi iniciado ou progrediu significativamente em 1994. Como resultado, houve a emergência das primeiras falências de grandes e importantes firmas; esse processo acelerou-se em 1995.

\section{Gestão corporativa em firmas \\ privatizadas por meio de voucher}

Como são administradas as firmas tchecas privatizadas? Se forem omitidos os casos em que elas de fato têm um proprietário ou proprietários individuais como resultado de sua privatização, ou os casos em que foram compradas por um investidor estrangeiro, segue-se do mencionado até aqui sobre a privatização voucher, que a resposta a essa pergunta é complexa. Também deve ser percebida qual é a estrutura dos organismos estatutários da empresa e de suas inter-relações, de acordo com o Código Comercial Tcheco.

A reunião geral dos acionistas nas companhias públicas limitadas tchecas elege e recompõe o Conselho de Diretores e o Conselho Supervisor; alternativamente, pelo status da companhia pode-se organizar tais relações de maneira mais próxima ao modelo alemão, no qual, na reunião geral se elege e se recompõe o Conselho Supervisor e este, por sua vez, elege e recompõe o Conselho de Diretores; essa disposição, contudo, é muito rara na prática. O Conselho de Diretores elege e recompõe o presidente do Conselho de Diretores, o cargo mais elevado 
da companhia. Além dessas estruturas, as companhias tchecas geralmente mantêm administrações constituídas de administrador geral e administradores-chefes responsáveis por áreas individuais. São essas administrações, e não o Conselho de Diretores, que geralmente controlam a vida cotidiana das companhias. O administrador geral e os administradores-chefes são nomeados pelo Conselho de Diretores.

O administrador geral geralmente é eleito também para o cargo de membro e presidente do Conselho de Diretores; outros membros do Conselho são, em geral, representantes dos acionistas; às vezes, alguns dos administradoreschefes, depositários (na qualidade de representantes de bancos) e/ou especialistas externos são também eleitos como membros do Conselho de Diretores.

A composição do Conselho Supervisor tem geralmente estrutura semelhante - representantes dos proprietários, bancos e administração. De acordo com o Código Comercial, um terço dos membros do Conselho Supervisor são representantes dos empregados; estes, na realidade, são também administradores (chefes). Normalmente, o Conselho Supervisor não é numeroso: um mínimo de três membros, é bastante comum - ao passo que o Conselho de Diretores, de forma geral, tem o dobro desse número.

A freqüência de reuniões dos dois Conselhos é baixa. Na realidade, os membros internos dos Conselhos, isto é, os administradores da companhia têm (às vezes juntamente com representantes dos seus credores, ou seja, os bancos) uma influência decisiva sobre os dois Conselhos. A administração, como o principal controlador das informações internas sobre a companhia, é geralmente capaz de persuadir os outros membros do Conselho sobre a racionalidade das suas propostas. Na maioria das vezes, os dois Conselhos não intervêm muito nos processos de tomada de decisão administrativa.

Portanto, a despeito da importância do papel específico de todos os agentes envolvidos (inclusive funcionários, proprietários, credores, clientes etc.), a posição dos administradores na estrutura de governança da corporação parece ser, até agora, a mais forte da economia tcheca (provavelmente ainda maior, se comparada à sua posição antes da privatização), embora o papel dos bancos, freqüentemente duplo, como credores e proprietários de companhias (através dos FPIs), também tenha crescido de maneira significativa e pareça ser decisivo para o futuro (de uma perspectiva de longo prazo). Assim, quando se fala sobre a revolução corporativa ou administrativa e/ou sobre a revolução bancária na economia tcheca, reflete-se dois importantes lados da realidade tcheca contemporânea. Entretanto, não ficou claro até o momento quais aspectos dessa complexa realidade serão dominantes.

\section{Considerações finais}

O processo de privatização foi o momento mais importante da vida de todas as empresas tchecas no período de 1991-1993 (para algumas delas, esse 
processo continuou até 1995). Foi uma tarefa imensa, que consumiu durante muito tempo recursos das suas administrações. Elas precisaram concentrar atenção, esforço e capacidade sobre esta questão (inclusive explicitar a carga administrativa - a privatização significou, entre outras coisas, excessivo trabalho burocrático, com provas de direitos de propriedade de bens imóveis, preenchimento de inúmeros formulários e documentos que acompanhavam os projetos de privatização, em um grau que excedeu em muito o ritmo normal das atividades administrativas das administrações superiores). Resultado negativo desse período febril foi que as administrações das empresas privatizadas não conseguiram dedicar atenção apropriada às tarefas de planejamento estratégico, administração comercial, desenvolvimento de produtos, problemas de tecnologia, produção, eficiência etc., isto é, às questões cuja coordenação é crucial para o bom desempenho de uma empresa. Os principais pontos fracos das firmas tchecas, atualmente, muitas vezes são conseqüências ou foram acelerados por essa preocupação com a privatização que durou três ou quatro anos (5).

Antes do próprio processo de privatização, houve um período de agonia pré-privatização na República Tcheca (6), período caracterizado por incerteza e mentalidade de curto prazo dos dirigentes, mais claramente expressa nas atividades de privatização espontânea (7).

Por outro lado, o desenvolvimento ocorrido nos dois últimos anos mostra que a privatização é importante: mesmo que as tendências gerais de comportamento sejam idênticas nas firmas já privatizadas e nas ainda não-privatizadas, existem diferenças significativas entre os dois grupos. Em primeiro lugar, exigese que as firmas privatizadas gerem lucro, enquanto as ainda não-privatizadas têm a chance de serem deficitárias (loss-makers)e, dessa maneira, realizarem uma restruturação financeira mais dura.

Baseada na instituição do projeto individual, a Grande Privatização Tcheca foi um processo altamente descentralizado, em que o governo basicamente definiu as regras de acordo com as quais os indivíduos, as empresas, as administrações e os outros atores deveriam atuar. Seu sucesso dependeu de iniciativa privada de baixo para cima. Ficou comprovado que a força mais importante neste processo foram as administrações das EEs que, de fato, também preencheram muitas das funções de proprietário: o governo primordialmente aprovou ou rejeitou o que as administrações lhe submeteram. Assim, as administrações estavam definindo o arranjo e o conteúdo da privatização em cada caso particular, estabelecendo a agenda segundo a qual procederiam. As administrações da maioria das empresas detinham o monopólio das informações e, tal fato, naturalmente, constituiu a propícia posição inicial para conquistar suas metas. Conforme mencionam Buchtíková (1993) e Capek, 1995), há uma "semelhança notável" entre a relação governo-empresa "de cima para baixo" no processo de planejamento nas economias centralmente planejadas e no processo de privatização baseado em projetos individuais: as propostas dos planos das empresas, bem como as do projeto (básico) de privatização, foram submetidas por empresas 
bem-informadas a um governo desinformado, o qual teve de decidir sobre elas sem o conhecimento relevante necessário.

Da observação do curso do processo de privatização na República Tcheca, pode-se derivar uma espécie de modelo geral de comportamento das administrações. A primeira alternativa pela qual as administrações estavam tipicamente optando era a possibilidade de aquisição alavancada de ações (leveraged buy-out) (venda direta). A pergunta que deveriam responder era: a aquisição alavancada seria viável? Se a resposta (baseada em análise estritamente econômica) fosse afirmativa, então elas propunham e forçavam tal opção. Se não fosse - a razão para uma resposta negativa referia-se, principalmente, à taxa de juros e ao volume dos encargos do serviço da dívida depois da privatização - então, geralmente optavam pela privatização por voucher como a segunda melhor (second best) solução, a qual lhes propiciava forte controle corporativo sobre os frágeis e, de fato, impotentes proprietários institucionais (FPIs). O brilhante raciocínio dos administradores tchecos revelou seu poder nesse momento, quando, ao contrário dos políticos ou dos analistas independentes, previram corretamente o desfecho do experimento voucher na área dos direitos de propriedade e do controle corporativo (pelo menos em perspectiva de curto e médio prazos) antes de sua implementação.

A estabilidade dos proprietários e a continuidade da administração estão relacionadas com as estratégias de privatização das administrações das EEs na maioria dos empreendimentos tchecos. Em geral, não houve grandes mudanças quanto ao pessoal nas (antigas) EEs desde o final dos anos 80 .

Finalmente, o verdadeiro propósito da privatização foi solucionar o problema da definição dos imprecisos direitos de propriedade, ou da propriedade ausente, problema herdado do planejamento central; conseqüentemente, solucionar uma das fontes da agonia pré-privatização (além da incerteza radical das EEs e de suas administrações com relação ao seu futuro). O governo tencionava encontrar um proprietário concreto para qualquer parte da até então propriedade estatal anônima. Acreditava-se que o controle da propriedade das empresas era pré-requisito crucial para o seu desempenho econômico eficiente. A privatização através de voucher, contudo, na maioria dos casos, pareceu levar a resultados bem distantes da meta neoliberal oficialmente declarada. Os novos proprietários são principalmente institucionais (FPIs), sem capacitação adequada para administrar, controlar e supervisionar. Eles detêm grande propriedade em várias dezenas e até centenas de negócios, mas apenas limitadas capacidade e habilitação profissionais qualificadas. E, da mesma forma que no modelo do planejamento central, não têm informações suficientes - o monopólio da informação é detido pelas administrações das empresas. Nessa situação, a unidade de interesses das empresas (suas administrações) e dos FPIs e/ou bancos, na qualidade de proprietários, é pré-condição necessária para a desejada eficiência operacional e de desempenho das antigas EEs. Por outro lado, sob qualquer colisão ou contradição de interesses entre proprietários e administradores, surge o problema da agência; e, na situação tcheca específica, com lacunas legais e morais (além de baixa disci- 
plina financeira, mercados monopolistas e bolsa de valores frágil e de pouca projeção), esse problema pode ter efeito destrutivo. Pode, de fato, estar prolongando pelo menos parte das características do período da agonia pré-privatização, situação na qual as empresas não têm qualquer controle eficaz por parte de seus proprietários (suas administrações têm toda a liberdade de agir sem serem cerceadas). Logo, a privatização por voucher parece resultar numa institucionalização em larga escala e em prazo consideravelmente longo da propriedade ausente.

Além disso, a maioria dos empreendimentos está em situação na qual não há qualquer proprietário principal e os FPIs, que controlam pacotes menores de suas ações, não são capazes de (ou não estão dispostos a) encontrar soluções mutuamente acordadas devido a estratégias e interesses divergentes. Exemplo de uma típica situação contraproducente desse tipo é quando existe conflito no conselho de diretores de uma empresa entre os representantes dos FPIs, que preferem acumulação de capital e crescimento, e aqueles que preferem altos dividendos.

Conseqüentemente, pode-se concluir que a privatização é importante, mas em menor grau que a mercantilização (marketization) como tal. Ou seja, se não se adotar essa abordagem generalizante, pode-se dizer que são importantes somente a forma particular e o conteúdo da privatização. Em resumo, a proposição resultante da evidência empírica obtida em pesquisa de campo (Mertlík, 1995; Capek, 1995) é que o processo de privatização predetermina o futuro de cada companhia; por outro lado, não há correlação significativa alguma entre a forma de privatização e o desempenho econômico (que inclui eficiência, produtividade e lucratividade) das companhias privatizadas. Duas companhias com condições iniciais semelhantes e privatizadas da mesma maneira podem trilhar caminhos de desenvolvimento completamente diferentes, enquanto, por outro lado, o desenvolvimento de outras duas companhias com condições iniciais semelhantes, mas com histórias de privatização bem diferentes, poderá ser muito parecido.

Outra conclusão é tornar-se agora evidente a instabilidade da estrutura dos direitos de propriedade emergente e da governança corporativa resultante criadas pela privatização por voucher. Além do acima mencionado da privatização real, isto é, da transferência dos direitos de propriedade daqueles que obtiveram os títulos de propriedade na privatização voucher para os proprietários seguintes (que geralmente incorporam, entre outros, importantes processos de re-concentração), é importante mencionar que todos os agentes envolvidos - nominalmente as administrações das empresas privatizadas, bancos e FIPs - estão exigindo cada vez mais uma mudança institucional (legislativa) da regulamentação existente (por exemplo, a remoção do limite de $20 \%$ para a participação dos FIPs em uma companhia, o que possibilitaria concentração de capital significativamente mais elevada nos FIPs). Tal necessidade de mudança agora também se reflete na esfera política $(8)$.

Outro passo estabilizante importante e viável - embora altamente controverso - poderia ser, naturalmente, a possível venda da participação acionária cen- 
tral do governo (FNP) em inúmeras empresas e explicitamente em bancos e outras instituições financeiras (como companhias de seguro) para genuinos investidores privados, o que praticamente significa capital estrangeiro; a decisão sobre tal passo, contudo, cabe exclusivamente à área política ou de julgamento de valor e, portanto, longe do domínio da análise econômica descritiva (por mais sérias que possam ser as suas conseqüências econômicas).

E por último, nem por isso menos importante, vale a pena repetir uma vez mais que o importante processo da privatização secundária silenciosa já se realiza no mercado de capitais, no qual os FIPs estão, por diversas razões (a necessidade de restruturação permanente de sua carteira corrente, mas principalmente a de liquidar parte de seus ativos para conseguir atender a seus passivos), vendendo parte das ações de sua carteira. Os compradores são, freqüentemente, investidores estrangeiros, mas também investidores privados tchecos; portanto, a estrutura dos direitos de propriedade nas companhias privatizadas por voucher está agora mudando de maneira silenciosa e invisível.

Notas

1 Para uma descrição analítica das políticas macroeconômicas de 1991 e a conseqüente abrupta queda da inflação (slumpflation), veja Mertlík, 1993a, 1993b.

2 De acordo com a legislação tcheca (tchecoslovaca), a empresa estatal (EE) é uma unidade de propriedade integrada com fins lucrativos, pertencente ao Estado, com um passivo limitado garantido por seu patrimônio. O patrimônio das EEs é indivisível, isto é, não está dividido em participações de propriedade. A organização orçamentária é não-lucrativa - não fornece serviços comercializáveis - e, portanto, sem renda (receita) própria. É financiada pelo orçamento público e a propriedade, em sua administração operacional, pertence a seu fundador, ou seja, ao governo (ou a uma municipalidade). Outra organização não-lucrativa é a participativa; ao contrário da orçamentária, a organização participativa fornece (pelo menos parcialmente) serviços comercializáveis e, portanto, parte de seus recursos financeiros (meios extra-orçamentários) provém de sua receita de mercado, enquanto o restante - montante fixo a ela alocado a cada ano - é financiado pelo orçamento (contribuição orçamentária).

3 Chaloupka et al. (1993), analisam as pré-condições sócio-culturais do processo de privatização.

4 Para uma história detalhada da privatização tcheca, inclusive seus números, veja Buchtiková (1995).

5 Análise detalhada sobre a vantagem competitiva da indústria tcheca e de sua mudança durante a transformação encontra-se em Mertlík (1994a).

6 Para uma descrição da agonia pré-privatização, veja Mertlík (1993a, 1994b); quanto à análise dos padrões comportamentais mais característicos das firmas antes e durante $\mathrm{o}$ processo de privatização, Buchtíková (1993), Capek (1995) e Mlcoch (1993).

Estudos AvanÇADOS 10 (28), 1996 
7 A economia tcheca não experimentou o mesmo tipo de privatização espontânea baseada em atividades econômica e socialmente produtivas e fundamentalmente legais, como aconteceu na Hungria no final dos anos 80 (Voszka, 1993). Ao contrário, houve uma forma tchecoslovaca desregrada de privatização espontânea, baseada em atividades criminosas ou semicriminosas das administrações das EEs que foram, pelo menos a curto e médio prazos, contraproducentes, tanto econômica quanto socialmente (Mertlík, 1993b; Mlcoch, 1993). Ao contrário do caso húngaro, no qual o processo de privatização espontânea não foi uma verdadeira privatização, mas simplesmente uma nova forma de operacionalização dos direitos de propriedade pública, no caso tcheco, a privatização espontânea foi verdadeira, ou seja, constituiu uma transferência de direitos de propriedade de mãos públicas para mãos privadas por meio de atividades econômicas informais.

8 Em fevereiro de 1995, o governo preparou uma versão preliminar de emenda referente à Lei de Investimento Coletivo (lei sobre companhias de investimento, FPIs e fundos mútuos), com a finalidade de redefinir os poderes dos FPIs nas empresas sob seu controle. A emenda foi rejeitada pelo Conselho dos Ministros Econômicos do governo; nova versão foi preparada e novamente rejeitada pelo mesmo organismo governamental em agosto de 1995, devido principalmente à discordância mútua entre ministros econômicos sobre a natureza das mudanças legais necessárias; contudo, a despeito desses conflitos, a questão se deve à atual aceleração do processo de privatizaçãa secundária que se torna cada vez mais tumultuado.

\section{Referências bibliográficas}

BUCHTÍKOVÁ, A. Ekonomická historie zániku Ceskoslovenska. Proces privatizace (A história econômica da quebra (break-up) da Tchecoslováquia. O processo de privatização). Praga, Institut Economie CNB (Instituto de Economia do Banco Nacional Tcheco), 1995.

BUCHTÍKOVÁ, A. \& CAPEK, A. Privatization in the Czech Republic: pivatization strategies and priorities. Praga, Institut Ekonomie CNB (Instituto de Economia do Banco Nacional Tcheco), 1993.

CAPEK, A. Financial restructuring of Czech enterprises. Paris, Maison des Sciences de l'Homme, 1995.

CHALOUPKA, O.; KLUSÁK, M.; MASKOVÁ, E. \& MERTLÍK, P. Transforming a centrally planned economy into a market economy: the case of Czechoslovakia. In: Sjöstrand, S.-E. (ed.). Institutional change: theory and empirical findings. Nova Iorque, M.E. Sharpe, 1993.

CHLUMSKÍ, J. Strategie otervíráni hospodársky stredne vypinutych zemí (A estratégia de abertura de países de médio desenvolvimento). Praga, VSE, 1994.

MERTLÍK, P. The deformations of the price relations and the antimonolpoly function of the government in the process of economic reform in Czechoslovakia. Prague, Economic Papers, n. 2(a), 1993. 
MERTLÍK, P. Product slump in Czechoslovakia: a critical overview. Human Systems Management, n. 4. 1993b.

MERTLÍK, P. The role of the government in industrial restructuring: the Czech case. Cracóvia, UCEMET, 1994(a).

Transformation of the Czech and Slovak economies 1990-1992: design, problems, costs. In: L. Hausner, J., Jessop, B., Nielsen, K. (eds.) Strategic choice and path-dependency in post-socialism. Aldershot, Edward Elgar, 1994(b).

Legal and organizational restructuring of Czech enterprises. Paris, Maison des Sciences de l'Homme, 1995.

MLCOCH, L. The behavior of the Czechoslovak enterprise sphere. Praga, EÚ CSAV, 1992.

The dynamics of changes in behavior within the Czech enterprise sphere.

Praga, SÚ AV CR, 1993.

Privatizace jako problém institucionálniho evolucionismu (A privatização como um problema de evolucionismo institucional). Finance a úver, n. 4, 1995.

SLALICKY, J. Odpoveo na interpelaci poslance Jozefa Wagnera (Propostas à interpelação do deputado Josef Wagner). Snemovní tisk 1329 A (Gazeta da Câmara de Deputados 1329 A). Praga, Poslanecká snemovna Parlamentu Ceské republiky. Câmara dos Deputados do Parlamento Tcheco, 1994.

STARK, D. Recombinant property in East European Capitalism. Budapest. Collegium and Ithaca, Cornell University, 1994.

VOSZKA, É. From renationalization to redistribution? Budapest, Kopint-Datorg/, 1993.

Pavel Mertlík é pesquisador do Instituto de Economia do Banco Nacional Tcheco e professor do Instituto de Estudos Econômicos da Faculdade de Ciências Sociais da Universidade Charles, de Praga.

Tradução de Vera de Paula Assis. Revisão de Lenina Pomeranz. O original em inglês Czech privatization: from public ownership to public ownership in five years? - encontra-se à disposição do leitor no IEA-USP para eventual consulta.

Versões anteriores deste artigo foram apresentadas em Transformação em processos Seminário de acompanhamento do projeto de pesquisa internacional Europa Central e Oriental 2000 organizado pela Villággazdasági Kutató Intézet (Instituto para Economia Mundial) da Magyar Tudományos Akadémia (Academia Húngara de Ciências), Budapest, Hungria, em fevereiro de 1995, e na Conferência sobre a Europa Central e Oriental: 5 Anos, organizada pelo Centro para Pesquisa de Atividade Comercial na Europa Oriental (CREEB - Centre for Research into East European Business) do Buckinghamshire College da Universidade de Brunel, Chalfont St. Giles, Inglaterra, em junho de 1995. Esta versão final do artigo foi apresentada na $7^{\text {a }}$ Conferência Anual da Associação Européia para a Economia Política Evolutiva (EAEPE - European Association for Evolutionary Political 
Economy) Economias e Sociedades em Tranformação: Rumo a uma Teoria Institucional de Mudança Econômica, Cracóvia, Polônia, em outubro de 1995.

O autor agradece ao Institut Für die Wissenschaften vom Mensch (Instituto de Ciências Humanas), Viena, Áustria, ao Conselho Britânico e à Nadáni Josefa Marie; à Zdenky Hlávkovych (Fundação Hlávka), Praga, pelo apoio que possibilitou essas apresentações. As informações contidas no artigo foram obtidas durante a participação do autor em projetos de pesquisa Reestruturação de empresas em diferentes estágios da transformação da propriedade: a República Tcheca e a Polônia (Programa PHARE/ACE, Projeto n ${ }^{\circ} 92$ 0223R) e Futuro da indístria na Europa Central e Oriental (Programa STD-2 EC, referência ${ }^{\circ}$ CIPACT 930085). As opiniões expressas no artigos são da autor e não coincidem necessariamente com as do Banco Nacional Tcheco.

Reproduzido de Prague Economic Papers, v. IV, n. 4, 1995, com a permissão da Universidade de Economia. W. Churcill Sq. 4. Praga 3, 130 67. República Tcheca. 
RESUMO - OS ARTIGOS INCLUIDOS NESTE DOSSIĖ dizem respeito ao processo de transformação dos países do Leste europeu, que começou com a perestroika na União Soviética e foi rapidamente seguido pelos países da Europa Central e Oriental, organizados de acordo com o modelo soviético. Esse processo está agora completando um decênio de experiência e conhecimento e dando lugar a uma literatura considerável, nos vários aspectos que compõem a transformação.

O ARTIGO DO DOUTOR LÁsZló CSABA oferece uma visão geral do processo, enfatizando sua natureza peculiar, que tem a ver com o modelo histórico seguido pela industrialização socialista desses países. A primeira parte do artigo faz uma análise desse modelo e de suas crises, concluindo que as causas do que ele chama de impasse da modernização são de caráter estrutural e como tais devem ser entendidas e tratadas. A segunda parte examina a transformação como um novo caminho de modernização, cobrindo o que o autor entende serem os problemas importantes para tirar esses países do beco sem saída: os problemas de longo prazo, a edificação instituicional e as mudanças nas normas de comportamento. $\mathrm{O}$ artigo termina com um apanhado geral e perspectivas futuras, especialmente as relativas à associação à União Européía.

O ARTIGO DA DOUTORA TATIANA ZASLAVSKAIA contém uma visão bastante ampla da estratificação social da Federação Russa e de sua dinâmica, resultantes da tranformação sistêmica pela qual o país está passando. O artigo é resultado de pesquisa original, feita com base em uma monitoria das reformas conduzidas há três anos pelo Centro Russo de Pesquisa de Opinião Pública. Além de definir as metas da pesquisa e os métodos empregados, o artigo traça a estrutura da sociedade russa, identifica seus diferentes grupos e camadas com as correspondentes características sócio-demográficas e status sócio-econômico, bem como discute a distribuição de renda em sua dinâmica durante o período sob investigação. A principal conclusão da pesquisa - somente parte dela sendo assunto do artigo - é que o processo de transformação sistêmica é profundo e marcado por contradições, refletindo uma combinação de modernidade e regressão social, sem definir qual das duas tendências prevalece. O problema central é agora a adaptação dos grupos de massa às novas condições sociais, que podem levar a sérios problemas sociais e políticos. Em vista disso, o papel do cientista social é avaliar corretamente os resultados do processo de transformação e o seu grau de conformidade com os interesses sociais dos grupos de massa e camadas da população e com a sua capacidade de adaptação ao mercado. Essa seria sua contribuição à formulação de uma estratégia para tirar o país da crise.

O artigo do doutor Tadeusz Kowalik trata da distribuição de renda na Polônia no período da transformação sistêmica. Começa com um apanhado geral da discussão teórica sobre o assunto e segue com a demonstração do que ele entende por revolução na estrutura de renda da Polônia, baseado principalmente em três estudos feitos no Instituto de Economia da Academia Polonesa de Ciências. Os dados empregados são do período 1990-1993 e exploram a estrutura bem como a dinâmica da renda per capita da população, indicando a polarização como a principal característica das mudanças sofridas. No artigo, conclui que ela é o resultado tanto da ação do governo quanto expontânea, e identifica o desafio que a elite polonesa enfrenta: deixar a formação de renda para o mercado ou optar por uma política sócio-econômica com vistas à redução de desigualdades. 
O ARTIGO DO DOUTOR PAVEL MERTLIK é a respeito de um problema específico no processo de transformação: a privatização. Está baseado em projetos diferentes, realizado com a participação do autor. Após introduzir brevemente as reformas tchecas, o artigo descreve minunciosamente o plano de privatização e a estrutura de propriedade resultante de sua implementação. Os parágrafos seguintes são dedicados à análise do modus operandi do setor de propriedade do Estado e ao controle da gerência das firmas privatizadas por vouchers (cheques de privatização). As principais conclusões do trabalho são: primeiro, que o processo de privatização determina o futuro de cada companhia e que não há correlação siginificativa entre a forma de privatização e o desempenho econômico das companhias privatizadas; segundo, que a instabilidade da estrutura dos direitos de propriedade emergente e do controle da gerência resultante da privatização por vouchers torna-se agora aparente, com todos os agentes envolvidos, exigindo cada vez mais uma mudança institucional das regras existentes; e terceiro, que a privatização secundária silenciosa já avança nos mercados de capital e, conseqüentemente, que a estrutura dos direitos de propriedade em companhias privatizadas por vouchers está tácita e invisivelmente mudando.

ABSTRACT - THE ARTICLES INCLUDED IN THIS DOSSIE concern the process of transformation of Eastern Europe countries, that began with the perestroika in the Soviet Union and was rapidly followed by the countries of Central and Eastern Europe, organized under the soviet model. This process is by now completing almost a decennium and the amount of experience and knowledge about it, is giving place to a considerable literature, on the various aspects that conform the transformation. The articles here included cover some of them, of the highest importance for the understanding of the debate around the transformation.

DR. LASZLO CSABA'S ARTICLE gives a general view of the process, stressing its "peculiar nature", which has to do with the historical pattern followed by the socialist industrialisation of these countries. The first part of the article gives an overall analysis of this pattern and its crises, concluding that the reasons of what he calls the modernization dead end are of structural character and that so shoud they be understood and dealt with. The second part of the article concerns the transformation as a new path of modernization, covering what the autor understands to be the relevant issues for getting these countries "out of the dead end alley": the long term problems, institutional building and changes in the behavioural norms. The article finishes with an overview and prospects, especially those concerned with the European Union membership.

DR. TATIANA ZASLAVSKAIA'S ARTICLE is a broad overview of the social stratification of the Russian Federation and it dynamics, as a result of the systemic transformation the country is undergoing. This article results from an original research, done on the basis of a three year monitoring of the reforms, conduced by the Russian Center of Public Opinion Research. Besides defining the goals of the research and the methods followed, the article traces the social structure of the Russian society; it identifies its different groups and strata, with the correspondent socio-demographic characteristics and socio- 
economic status, and it discusses the income distribution and its dynamics over the period under investigation. The main conclusion of the research - only part of it being the subject mather of the article - is that the process of systemic transformation is deep and marked by contradictions, reflecting the combination of modernisation and social regression, without definition of which of these trends prevails. The central issue is now the adaptation of the mass groups to the new social conditions, which may lead to serious social and political problems. In view of this, the role of social scientist is to correctly assess the results of the transformation process and the degree of its conformity with the social interests of the mass groups and strata of the population and with their capacity of adaptation to the market. This would be their contribution to the formulation of a strategy to take the country out of its crisis.

Dr.Tadeusz kowalik's article is concerned with the distribution of income in Poland in the period of the systemic transformation. It begins with an overview of the theoretical discussion over the issue, and follows with the demonstration of what he understands to be a "revolution" in the income structure in Poland, based mainly on three studies done at the Institute of Economics of the Polish Academy of Sciences. The data used concern the period 1990-1993 and explore the structure as well the dinamycs of the personal income of the population. Indicating social polarisation as the main characteristic of the changes undergone, the article concludes that it is a result of both government action and spontaneity, and identifies the chalenge facing polish elite: leaving income formation to the market or opting for a conscious socio-economic policy aimed at the reduction of inequalities ?

DR. PAVEL MERTLIK'S ARTICLE deals with a specific problem of the transformation process: privatization. It is based on different research projects, fulfilled with dr. Mertlik's participation. After briefly introducing the czeck reforms, the article describes very carefully the design of privatization and the ownership setup resulting of its implementation. The next paragraphs are dedicated to the analysis of the mode of operation of the former state-owned sector and to the corporate governance in voucher privatized firms. The main conclusions of the work are first, that the privatization process determines the future of each company and that there is no significant correlation between the form of privatization and the economic performance of privatized companies; second, that the instability of the emerged property rights setup and the resulting corporate governance created by the voucher privatization becomes now to be apparent, with all agents involved increasingly asking for an institutional change of the existing regulation; third, that the "silent secondary privatization"already proceeds in capital markets and hence, the structure of the property rights in voucher-privatized companies is silently and invisibly changing.

O abstract é de autoria da professora Lenina Pomeranz e a versão para o portugês da professora Martha Steinberg.

Estudos AvanÇAdos 10 (28), 1996 